\title{
INVENTARISASI ARACEAE DI HUTAN SIBAYAK 1 KECAMATAN SIBOLANGIT KABUPATEN DELI SERDANG SUMATERA UTARA
}

\author{
Melfa Aisyah Hutasuhut (melfa.aisyah@yahoo.com) \\ Program Studi Biologi Universitas Islam Negeri Sumatera Utara
}

\begin{abstract}
ABSTRAK
Tumbuhan Araceae merupakan salah satu jenis tumbuhan herba yang hidup di darat, diperairan, dan merambat pada pohon. Penelitian ini dilaksanakan pada bulan bulan September -November2019 di kawasan Hutan Sibayak I, Kecamatan Sibolangit, Kabupaten Deli Serdang, Sumatera Utara dengan menggunakan metode jelajah. Berdasarkan hasil pengamatan diperoleh 9 jenis Araceae, dengan 5 marga Araceae. Jenis tanaman tersebut diantara nyaColocasia esculenta (L) Schott, Homalomena humilis Hook, Homalomena propinqua Schott, Rhapidophora sp, Scindapsus rupestris Chevo \& Corner, Scindapsus pictus Hassk. Scindapsus officinalis Schott. Schismatoglottis triandra. Schismatoglotis calyptrate (Roxb).
\end{abstract}

Kata Kunci : Hutan Sibayak 1, Tumbuhan Araceae

\begin{abstract}
Aracea is one of the herbaceousplans which live at tersterian, aquatic and epifit. The research on the species of araceae plants was conducted from Septemberuntil November 2019 in the Sibayak 1 Forest Sibolangit sub-district, Deli Serdang district, North Sumatera. Sampling was done by explore method. This research obtained as many as9 spesies of Araceae whit 5 genus of Araceae.Nine species of Araceae were found, such asColocasia esculenta (L) Schott, Homalomena humilis Hook, Homalomena propinqua Schott, Rhapidophora sp, Scindapsus rupestris Chevo \& Corner, Scindapsus pictus Hassk. Scindapsus officinalis Schott. Schismatoglottis triandra. Schismatoglotis calyptrate (Roxb).
\end{abstract}

Keywords: Sibayak 1 forest, Araceae

\section{PENDAHULUAN}

Suku Araceae merupakan salah satu jenis dari tumbuhan herba yang hidup di darat (teresterial), di perairan (akuatik) dan merambat pada pohon (epifit)(Kurniawan et al., 2013). Tumbuhan Araceae banyak dikenal oleh masyarakat sebagai tanaman hias yang terdapat di pekarangan rumah, namun tumbuhan ini juga dapat ditemukan hidup liar di hutan. Kawasan beriklim tropik seperti Indonesia merupakan habitat yang sangat cocok bagi tumbuhan ini. Sekitar 90\% marga dan 95\% jenis Araceae hidup di kawasan tropic(Asih et al., 2014). Tanaman Araceae sangat dipengaruhi oleh faktor lingkungan seperti cahaya, kelembaban yang relatif tinggi, suhu udara berkisar $25-300^{\circ} \mathrm{C}$, pH tanah $5-7,5$ (Khoirul, 2014).

Karakteristik dari tumbuhan Araceae adalah perbungaan yang tersusun dalam bentuk tongkol (spadix) yang dikelilingi oleh seludang (spathe)tipe perbungaan uniseksual atau biseksual, serta dapat tumbuh sepanjang tahun (Van Steenis, 2008).. Menurut IPGRI (1999) bentuk seludang permukaan pada Araceae ada yang berbentuk tertutup, dimiringkan, datar, terbuka terkulai, tergulung, terputar, dan tergulung memutar. Sistem parakaran Araceae relatif dangkal dengan jangkauan akar di kedalaman 40-60 $\mathrm{cm}$ dari permukaan tanah (Muchtadi dan Sugiyono, 1992).Batang dibawah tanah membentuk umbi yang bentuk yang beragam seperti berbentuk kerucut, membulat, silindris, elips, halter, memanjang, datar, dan tandan (IPGRI, 1999). Tumbuhan Araceae memiliki daun tunggal, berbagi atau majemuk, tersusun sebagai roset akar, tersebar pada batang atau bersilangan dalam 2 baris.Helaian daun memiliki bentuk perisai, jantung atau tombak, anak panah (Tjitrosoepomo, 1996). Menurut IPGRI (1999) tepi daun pada tumbuhan Araceae memiliki bentuk rata, berombak (Undulate) atau bergerigi (Sinuate). Tumbuhan Araceae memiliki bentuk helaian daun yang bermacam-macam diantara nya bentuk terkulai, datar, mencekung atau cup, tegak keatas dan tegak kebawah. 
Melfa Aisyah Hutasuhut, Inventarisasi Araceae di Hutan Sibayak 1 Kecamatan Sibolangit Kabupaten Deli Serdang Sumatera Utara

JURNAL BIOLOKUS Vol.3 (1)

Suku Araceae memiliki 2500-3700 jenis dan 105-110 marga, umumnya terkonsentrasi di kawasan tropik, yaitu Asia Tenggara (termasuk Indonesia, Malaysia, Brunei Darussalam, Filipina, Singapura), Amerika dan Papua Nugini (Mayo et al. 1997). Indonesia sendiri terdapat 31 marga Araceae atau sekitar 25\% dari total marga di dunia dan pada umumnya tersebar di Sumatera, Jawa, Kalimantan, Sulawesi dan Papua. Sekitar 78\% atau 21 marga terdapat di kawasan timur Indonesia; delapan marga endemik di Pulau Kalimantan (Aridarum, Bakoa, Bucephalandra, Ooia, Phymatarum, Pedicellarum, Pichinia dan Schottariella) serta hanya satu marga yang endemik di Papua, yaitu Holochlamys (Mayo et al. 1997; Boyce et al. 2010).

Tumbuhan Araceae memiliki manfaat yang belum banyak diketahui oleh masyarakat baik dari segi ekonomi dan ilmiah. Pemanfaatan tumbuhan Araceae oleh masyarakat diantaranya sebagai tanaman hias, sumber pangan dan obat-obatan (Asih et al., 2014; Erlinawati \& Tihurua, 2013). Beberapa jenis di antaranya dimanfaatkan sebagai bahan makanan alternatif, contohnya dari jenis Colocasiaesculenta (L.) Schott (talas), Amorphophalluspaeoniifolius (Dennst.) Nicolson (suweg), dan Xanthosomasagittifolium (L.) Schott (keladi); sebagai tanaman hias karena berdaun dan berbunga indah, contohnya jenis-jenis Anthurium dan Alocasia; dan berkhasiat sebagai obat antibakteri, antioksidan, dan antikanker, yaitu Typhoniumflagelliforme Blume (keladi tikus) (Mohan et al., 2008; Mayo et al., 1997).

Hutan Sibayak I merupakan bagian dari Taman Hutan Raya Bukit Barisan yang memiliki kekayaan jenis-jenis tumbuhan yang sangat tinggi. Kawasan ini merupakan hutan yang memiliki peranan penting bagi daerah sekitarnya. Fungsi ekologis kawasan hutan tersebut adalah sebagai tempat tangkapan air (Cacthment Area), perlindungan mata air serta mencegah terjadinya erosi.Kurangnya informasi mengenai manfaat Araceae menyebabkan masyarakat tidak melakukan budidaya Araceae.Padahal Araceae memliki potensi pengembangan dibidang pangan yaitu sebagai diversifikasi pangan lokal dalam memenuhi kebutuhan masyarakat Indonesia terhadap kurangnya pasokan beras.Penelitian ini bertujuan untuk mengidentifikasi jenis-jenis tumbuhan Araceae yang ada di Hutan Sibayak 1 Kecamatan Sibolangit Kabupaten Deli Serdang.

\section{METODE}

Penelitian dilaksanakan pada bulan bulan Oktober - November2019 di kawasan Hutan Sibayak I, Kecamatan Sibolangit, Kabupaten Deli Serdang, Sumatera Utara. Alat yang digunakan dalam penelitian ini antara lain adalah plastik koleksi, etiket atau label, pisau, sekop, kamera, buku identifikasi tanaman, tabel pengamatan sementara, alat tulis. Bahan yang digunakan dalam penelitian ini yaitu tanaman famili Araceae yang terdapat di lokasi penelitian.

Metode yang digunakan adalah metode jelajahyaitu dengan cara melakukan pengamatan terhadap variabel pengamatan ciri morfologi Araceae di sepanjang aliran sungai Hutan Sibayak 1. Pengambilan data dilakukan dengan cara,Araceae dikoleksi, diberi label, dan dicatat ciri-ciri morfologi nya. Koleksi diletakkan di antara lipatan koran, selanjutnya koran dilipat, diikat dengan tali plastik, dimasukkan ke dalam kantung plastik yang berukuran 60 x $40 \mathrm{~cm}$ dan diawetkan dengan alkohol 70\%. Selanjutnya spesimen dibawa ke laboratorium untuk dikeringkan, dideskripsi dan diidentifikasi.

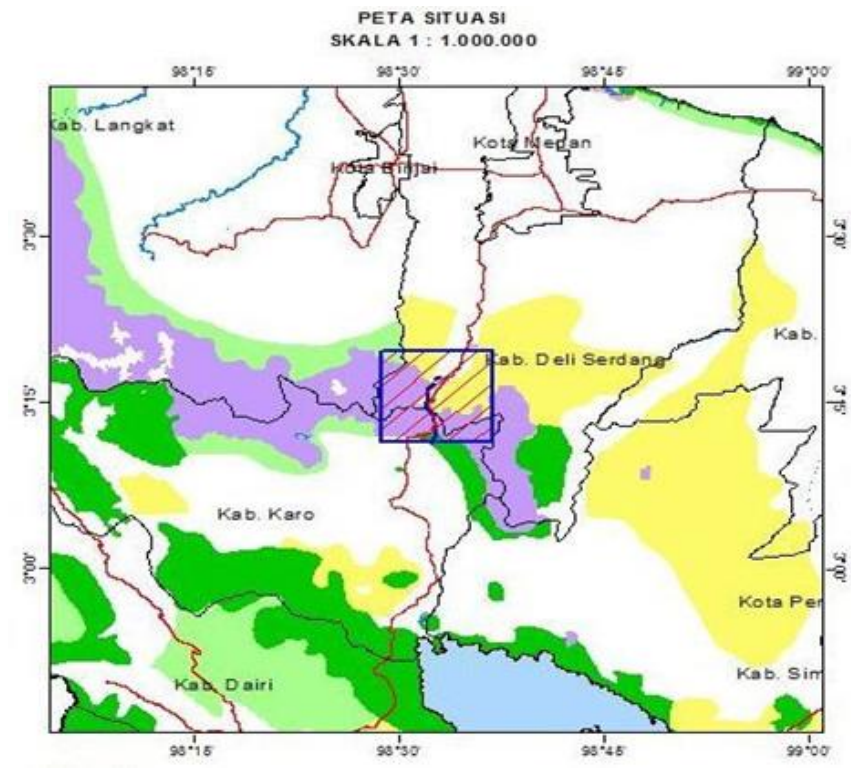

Gambar 1. Lokasi penelitian di Hutan Sibayak 1(Departemen Kehutanan 2009)

\section{HASIL DAN PEMBAHASAN}

Berdasarkan hasil pengamatan diperoleh 9 jenis tanaman dari golongan famili Araceae. Hasil identifikasi diperoleh 5 marga dan 9 jenis Araceae di hutan Sibayak 1. Jenis tanaman tersebut dari 5 marga Araceae yaitu genus Colocasia (1 jenis), Homalonema (2 jenis), Rhapidophora (1 jenis), Scindapsus (3 jenis) dan Schismatoglottis (2 
Melfa Aisyah Hutasuhut, Inventarisasi Araceae di Hutan Sibayak 1 Kecamatan Sibolangit Kabupaten Deli Serdang Sumatera Utara

JURNAL BIOLOKUS Vol.3 (1)

jenis).Identifikasi dilakukan mengacu pada the genera of Araceae (Mayo et al., 1997). Jenis Tanaman Araceae disajikan pada tabel 1.

Tabel 1. Jenis-jenis Araceae di Hutan Sibayak 1

\begin{tabular}{ll}
\hline & Nama jenis \\
\hline 1. & Colocasia esculenta (L) Schott \\
2. & Homalonema humilis Hook \\
3. & Homalomena propinqua Schott \\
4. & Rhapidophora sp \\
5. & Scindapsus rupestris Chevo \& Corner \\
6. & Scindapsus pictus Hassk \\
7. & Scindapsus officinalis Schott \\
8. & Schismatoglottis triandra \\
9. & Schismatoglottis calyptrate (Roxb)
\end{tabular}

\section{Deskripsi Morfologi Dari Jenis Araceae di Hutan Sibayak 1.}

\section{Colocasia esculenta(L) Schott}

Herba teresterial, tinggi tanaman $60 \mathrm{~cm}$. Batang; bulat, arah tumbuh batang tegak lurus, permukaan batang licin, hijau muda. Daun; panjang 10-15 cm, lebar $20-23 \mathrm{~cm}$, tunggal, bangun daun perisai, ujung meruncing, pangkal berlekuk (emarginatus), tepi daun rata, pertulangan daun menyirip (pinnenervis), daging daun tipis lunak, permukaan daun licin, daun hijau, letak daun berhadapan, panjang pelepah daun $25 \mathrm{~cm}$, hijau muda. Tumbuh pada tempat terbuka hingga agak terlindung pada ketinggian 500-2.000 m dpl. Tumbuhan ini memiliki banyak kultivar yang tersebar alami di tegalan maupun pekarangan penduduk. Akan tetapi, jenis liarnya banyak ditemukan di lantai hutan sekunder (Asih et al., 2015).

\section{Homalomena humilis Hook}

Herba terstertial yang memiliki daun yang relatif kecil dengan panjang daun sekitar $5-10 \mathrm{~cm}$ dan tinggi tanaman sekitar $15 \mathrm{~cm}$. genus yang sangat banyak jenisnya, diperkirakan lebih dari 500 jenis yang ada di dunia. Daun berbentuk jantung (cordatus) dengan bentuk ujung daun meruncing (acuminatus) dengan pangkal daun berlekuk (emarginatus) berpotensi untuk dikembangkan sebagai tanaman hias, (Munawarah et al, 2017).

\section{Homalomena propinqua Schott}

Herba tersterial. tumbuh di dataran rendah hingga dataran sedang, sebagian besar di lantai hutan, pinggir sungai, area curam dengan drainase yang baik dan kadang ada yang bersifat reofit. Tipe perbungaan bersifat uniseksual dengan seludang berwarna merah dan tidak ada penyempitan, (Munawarah et al, 2017).

\section{Schismatoglottis triandra}

Herba berstolon atau berumpun, tinggi 15 $60 \mathrm{~cm}$, jenis ini memiliki keragaman yang sangat tinggi; helaian daun berbentuk jantung - anak panah, kadang bulat telur atau lonjong memanjang dengan warna hijau kusam polos atau variegated. Tumbuh pada tempat terlindung, tanah berhumus di dalam hutan, di tepi sungai, tegalan, pada ketinggian 300-1.400 m dpl, (Asih et al., 2013).

\section{Schismatoglotis calyptrate (Roxb)}

Tinggi mencapai $60 \mathrm{~cm}$, daun seperti jantung hingga lonjong-memanjang, bunga dengan seludang atas menggembung dan berwarna hijau kekuningan-putih dan luruh setelah matang, tongkol menyempit di bagian tengah, berwarna putih. Tangkai daun halus. Helaian daun berbentuk lonjong. Perbungaan biasanya 1-8 secara bersamaan. Seludang bagian bawah berwarna hijau keputih-putihan. Seludang bagian atas berwarna krem sampai kuning kehijau-hijauan. Tongkol berukuran $3 / 4$ dari panjang seludang. Bagian atas akan terputus setelah selesai masa antesisseludang. Penyebarannya ada di kawasan Neotropis dan Asia tropis dengan keberagaman paling tinggi berada di hutan tropis Asia Tenggara yang berpusat pada tiga wilayah, yaitu Borneo, Sumatera dan New Guinea, (Asih et al., 2015).

\section{Rhapidophora sp.}

Epifit, batang persegi, berbuku-buku agak rapat, daun berbentuk elips-lonjong, asimetris, tebal dan kaku, daun bagian bawah berwarna hijau muda-keputihan, sedangkan daun bagian atas berwarna hijau. Tangkai daun berwarna hijau muda dan terdapat selubung pada tangkai daun muda. Batang berwarna hijau dengan jarak internodus $3 \mathrm{~cm}$. Tongkol memiliki panjang mencapai $7 \mathrm{~cm}$, tongkol dan seludang berwarna hijau, (Boyce et.al. 2010). 
Melfa Aisyah Hutasuhut, Inventarisasi Araceae di Hutan Sibayak 1 Kecamatan Sibolangit Kabupaten Deli Serdang Sumatera Utara

\section{JURNAL BIOLOKUS Vol.3 (1)}

\section{Scindapsus rupestris Chevo \& Corner}

Epifit, daun berbentuk bulat telur-lonjong, batang berbuku-buku, berwarna hijau, memiliki stolon, dari stolon tersebut tumbuh individu yang tegak terdiri dari 2-5 helai daun, tangkai daun panjang, kira-kira 1-2 panjang daun. Tangkai daun bulat. Helaian daun asimetris berbentuk jantung, (Boyce et al. 2010).

\section{Scindapsus pictus Hassk}

Perbungaan tunggal. Seludang berbentuk perahu. Tongkol berbentuk silinder. Tumbuhan ini biasanya hidup merambat pada pepohonan di daerah tropis dan subtropis yang lembap dan drainase air yang baik, daerah basah tropis dan subtropis pada dataran rendah hingga sedang (Boyce et al. 2010), menyukai lokasi dengan curah hujan yang tinggi.

Tumbuhan merambat, dengan tinggi rambatan dapat mencapai $30 \mathrm{~m}$. Batang berbentuk bulat dan menempel pada pohon rambatannya. Bunga tumbuh soliter pada ujung tunas batang. Dimanfaatkan sebagai tanaman obat. Daun pada umumnya tumbuh dan berkumpul pada bagian ujung batang, (Boyce et al. 2010).

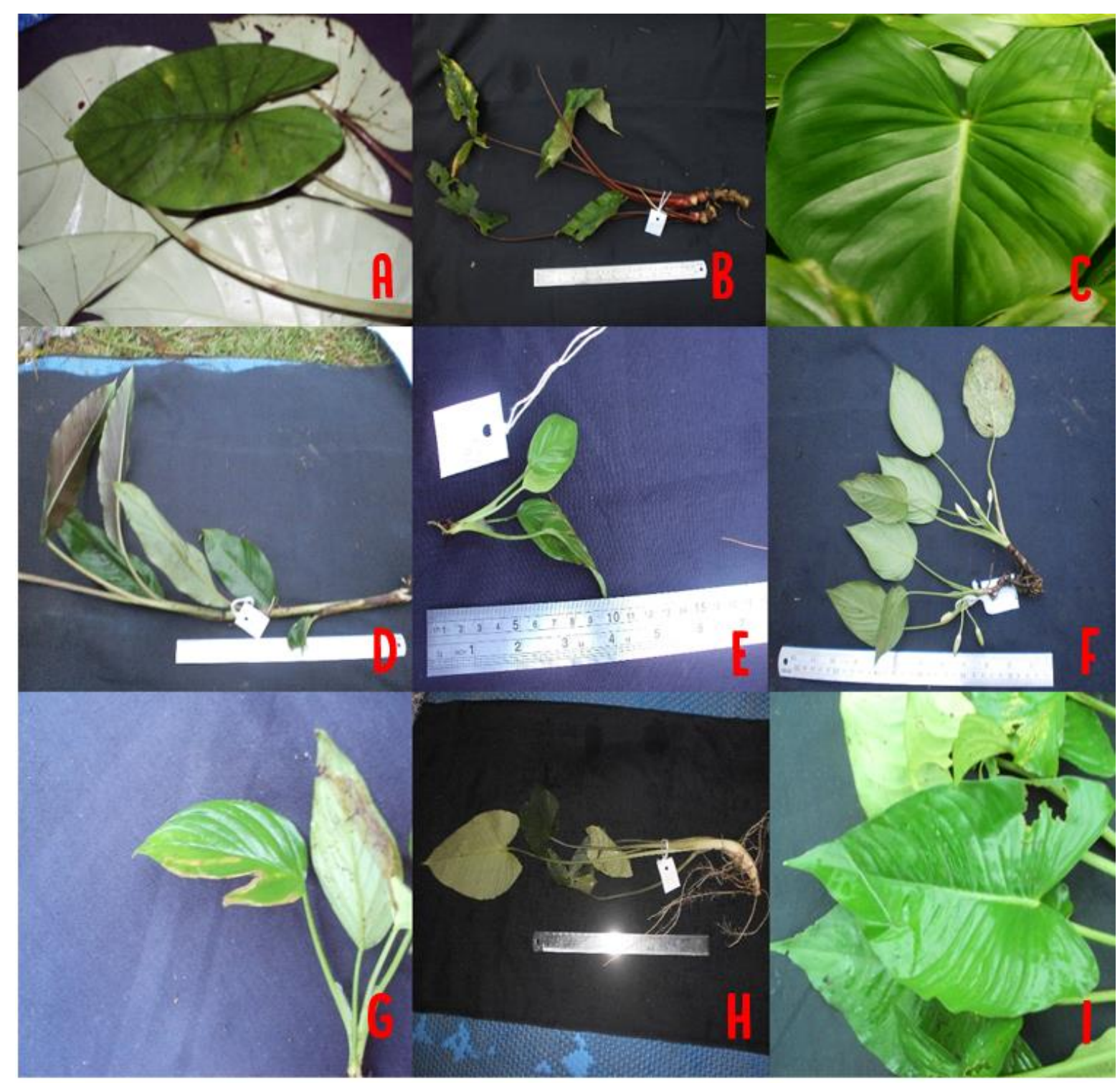

Gambar 2. A. Colocasia esculenta (L) Schott, B. Homalomena humilis Hook, C. Homalomena propinqua Schott, D.Rhapidophora sp. E. Scindapsus rupestris Chevo \& Corner. F.Scindapsus pictus Hassk, G.Scindapsus officinalis Schott, H. Schismatoglottis triandra,I. Schismatoglotis calyptrate (Roxb) 
Melfa Aisyah Hutasuhut, Inventarisasi Araceae di Hutan Sibayak 1 Kecamatan Sibolangit Kabupaten Deli Serdang Sumatera Utara

JURNAL BIOLOKUS Vol.3 (1)

\section{PENUTUP}

Suku Araceae memiliki batang basah (herba), daun berbentuk perisai, pangkal daun berlekuk, daging daun seperti kertas, susunan tulang menyirip, tipe batang basah berbentuk bulat dengan arah tumbuh tegak lurus. dan bunga yang terdiri atas seludang (spathe) dan tongkol (spadix). Umumnya hidup di tempat yang lembab dan terlindung. Ada yang hidup di darat (terestrial), mengapung di perairan (akuatik), merambat pada pepohonan (epifit). Selain dimanfaatkan sebagai tumbuhan hias, suku Araceae juga dimanfaatkan sebagai bahan pangan alternatif dan sebagai tumbuhan obat.

\section{REFERENSI}

Asih N.P.S., Warseno T., \& Kurniawan A. (2014) Araceae berpotensi obat di Kebun Raya "Eka Karya" Bali. Prosiding Semnas Biodiversitas, 3(1), 84-87.

Asih N.P.S., Warseno T., \& Kurniawan A. (2014). Studi inventarisasi Araceae di Gunung Seraya (Lempuyang), Karangasem, Bali. Prosiding Seminar Nasional Biodiversitas, 1(3), 521-527.

Asih N.P.S., Warseno T., \& Kurniawan A. (2013). Pelestarian dan Pemanfaatan Jenis-jenis Araceae Sebagai Tanaman Upacara Agama Hindu di Kebun Raya "Eka Karya" Bali. Prosiding Seminar Nasional Biodiversitas, 1, 115-121.

Boyce, P.C., Wong, S. Y., Ting, A. P. J., Low, S. E., Ng, K. K., Ooi, I. H. (2010). The Araceae of BorneoThe genera. Journal of Aroideana, 33, 3-73.

Boyce, P.C \& Wong, S. Y. (2012). The Araceae of Malesia I: Introduction. Malayan Nature Journal, 64(1), 33-67.

IPGRI. (1999). Descriptors for Taro. Italy: International Plant Genetic Resources Institute.

Khoirul, B. (2014). Identifikasi Tanaman Famili Araceae di Cagar Alam Tangale Kabupaten Gorontalo. Tesis. Universitas Negeri Gorontalo.

Kurniawan, A., Asih, N. P. S., Yusammi, P. C. \& Boyce. (2013). Studies on the Araceae of the Lesser Sunda Island I: New Distribution Record for Alocasia alba. Garden's Bulletin Singapore, 65(2), 157-162.
Linawati, I. \& Tihurua, E.F. (2013). Leaf Surface Comparison of Three Genera of Araceae in Indonesia. Buletin Kebun Raya, 16(2), 131145.

Mayo, S.J., Bogner, J., \& Boyce P.C., (1997). The Genera of Araceae. Belgium: Royal Botanical Garden, Kew.

Mohan, S., Abdul, A.B., Wahab, S.I.A., Al-Zubairi, A.S., Elhassan, M. M. \& Yousif, M., (2008). Antibacterial and Antioxidant Activities of Typhonium flagelliforme (Lodd.) Blume Tuber. American Journal of Biochemistry and Biotechnology, 4 (4), 402-407.

Muchtadi, T.R. \& Sugiono. (1992). Ilmu Pengetahuan Bahan Pangan. Departemen Pendidikan dan Kebudayaan. Direktorat Jenderal Tinggi Pusat Antar Universitas Pangan dan Gizi. Institut Pertanian Bogor, Bogor.

Munawaroh, E., Yuzammi, Solihah, S.M., \& Suhendar. (2017). Koleksi Kebun Raya Liwa, Lampung: Tumbuhan Berpotensi Sebagai Tanaman Hias. Jakarta: LIPI Press.

Sinaga, K.A., Murningsih, \& Jumari. (2017). Identifikasi Talas-talasan Edible (Araceae) di Semarang, Jawa Tengah. Jurnal Bioma, 19 (1), 18-21.

Tjitrosoepomo, G. (1996). Morfologi Tanaman. Yogyakarta: Universitas Gadjah Mada Press.

Van Steenis, CGGJ. (2008). Flora. Jakarta: Pradnya Paramita. 